\title{
Hypolipidemic Potential of Emblica officinalis (amla) Powder and Nutrition Counselling on Hyperlipidemic Subjects
}

\author{
Rachana Srivastava ${ }^{1}$, Poonam Khanna ${ }^{2}$, Jaswinder K Sangha ${ }^{3}$ \\ \{rahanasri@gmail.com ${ }^{1}$, poonamkhanna05@gmail.com ${ }^{2}$ \} \\ Women Scientist-DST, Department of Community Medicine and School of Public Health, \\ PGIMER, Chandigarh, India ${ }^{1}$ \\ Associate Professor, Department of Community Medicine and School of Public Health, PGIMER, \\ Chandigarh, India ${ }^{2 *}$ \\ Retired Faculty, Department of Food and Nutrition, Punjab Agricultural University, Ludhiana, \\ Punjab, India ${ }^{3}$
}

\begin{abstract}
Changes in lifestyle including dietary changes and reduced physical activity due to mechanization are contributing to the development of heart diseases. The use of drugs like statin for long term has led to serious side effects and reduced HDL-C synthesis. In view of these facts we planned the present study to evaluate the hypolipidemic potential of Emblica officinalis (amla) powder and nutrition counselling in hyperlipidemic subjects. 60 volunteer male hyperlipidemic subjects having total cholesterol $>200 \mathrm{mg} / \mathrm{dl}$, aging 39-49 years were selected from PAU Hospital and information regarding their background, lifestyle and medical family history was collected. Subjects were divided into 2 groups experimental E and control C. Experimental group was supplemented with $5 \mathrm{~g}$ E. officinalis powder and nutrition counselling and $\mathrm{C}$ was given nutrition counselling only for 90 days. A significant reduction in cereal, fats and oil and sugar and jaggery intake and an increase in intake of pulses, fruits, other vegetables, roots and tubers and milk was observed. Serum total cholesterol, LDL-C, triglycerides and VLDL-C in group E were significantly reduced after the study when compared with group C. An impressive 8.19 percent increase in HDL- C in the subjects of group E was observed. Therefore, supplementation of $\mathrm{E}$ officinalis (amla) powder and nutrition counselling can be an effective strategic dietary intervention for controlling serum lipid profile in hyperlipidemic subjects.
\end{abstract}

Keywords: Hyperlipidemia, Amla, Emblica officinalis, Nutrition counselling, supplementation.

\section{Introduction}

The condition of unusually elevated levels of lipids i.e. the fatty substance in the blood is known as hyperlipidemia. It is one of the risk factors of coronary heart diseases. To avert atherosclerosis induced disorders, hypolipidemic medications are widely used as prophylactic agents. But these 
hypolipidemic drugs are not free from adverse effects. [1] Worldwide interest in herbal and natural agents is mounting because of the protection they offer from many ailments as well as side effects of modern medicines. [2] In ancient times numerous herbs, spices and herbal products were used for treating various illnesses in India. With rich antiquity and know-how of using plant derived antioxidants and spices, health care expenditure can be downsized in countries like India where there is dearth of resources alongwith malnutrition [3]

Mortality due to cardiovascular diseases almost doubled in India between 1990 and 2016 from 1.3 million to 2.8 million deaths. [4] Statin, a drug used for treatment of hyperlipidemia works on the principle of inhibiting cholesterol synthesis and consequently inhibits HDL synthesis too in the body. Severe tendinopathy and musculoskeletal ailments have been reported in hyperlipidemic patients over the period of time. High-density lipoproteins (HDLs) have a preventive role in atherosclerosis as they uptake lipids from the vascular walls, impede LDL oxidation, impede the inflammation mechanism that triggering atherosclerosis. It is antithrombotic too and thus delays atherogenesis. [5] Since ancient times Emblica officinalis (EO) has sanctified place in Ayurveda (Indian traditional health care system). It has antidiabetic, hypolipidemic, antiseptic, antioxidant, antiulcerogenic, hepatoprotective, gastroprotective, and chemopreventive attributes. [6] Elevated HDL levels were reported in the rats consuming amla extract for 3 months alongwith significant reduction in cholesterol levels in liver, heart and kidney tissues. [7]

Therefore, the present study was planned to evaluate the hypolipidemic potential of Emblica officinalis (amla) powder and nutrition counselling in hyperlipidemic subjects. We chose Chakaiya cultivar for our study due to its high ascorbic acid content $(678 \mathrm{mg} / 100 \mathrm{~g})$. [8]

\section{Method}

Sixty male volunteer freshly diagnosed hyperlipidemic subjects having serum cholesterol more than $200 \mathrm{mg} / \mathrm{dl}$ were selected from OPD of Punjab Agricultural University Hospital, Ludhiana. The purpose of the study was explained to them and written consent of the subjects was also sought. The experiment design was approved by our institutional ethical committee. The subjects were divided into two groups of 30 each: Group E: Supplemented with Emblica officinalis powder and nutrition counselling Group C: Control (provided with nutrition counselling only). Data of the subjects was collected i.e. information about their age, qualification, occupation, lifestyle and medical history by a . The E. officinalis powder sachets were given daily to the subjects for 90 days and all the subjects (supplemented + control) were given nutrition counselling about management of hyperlipidemia with diet and exercise, twice a month i.e. 6 times in the study period through individual contacts. Relevant educational material in form of pamphlets and booklets was also distributed among them for better understanding and retention. At the beginning and end of the treatment period serum lipid profile, dietary intake and anthropometric indices of the subjects were assessed. Dietary intake of the subjects was calculated by using Indian food composition tables given by ICMR 
Plant material/supplement preparation-Emblica officinalis (Chakaiya cultivar) fresh $135 \mathrm{~kg}$ were procured from Research station Balowal, PAU. To process E. officinalis into powder the fruits were washed thoroughly with running water, wiped with a clean cloth and dried in cabinet drier at $61^{\circ} \mathrm{C}$ for 24 hours. After 24 hours of drying, fruits were destoned and again placed in cabinet for 72 hours and dried completely and kept in a dessicator till cooled. After that dried E.officinalis fruits were grounded finely into powder and stored in airtight containers away from sunlight. The powder so obtained was sealed packed in $5 \mathrm{~g}$ zip sachets to avoid any chance of exposure to atmospheric conditions and moisture reabsorption; which contained 50mg vitamin C. [9] All data is expressed as mean \pm SE. Student's ' $t$ ' test was used to evaluate the statistical significance. [10]

\section{Results}

The selected 60 volunteer hyperlipidemic males were in the age group of 39- 49 yrs the fourth decade of life is considered as the prime period of developing risk of coronary heart disease. Major job responsibility of the subjects was deskwork revealing a sedentary lifestyle pattern. 77 percent group $\mathrm{E}$ and 70 percent in group $\mathrm{C}$ were not in habit of doing exercise. 40 percent in group $\mathrm{E}$ and 20 percent in group $\mathrm{C}$ consumed alcohol 1-2 times in a week. Most of the subjects had family history of metabolic disorders like obesity and diabetes 33.33 and $26.67 \%$ in group E and 40 and $26.67 \%$ in group C. The data depicted that majority of the subjects i.e. 80 percent in group $\mathrm{E}$ and 90 percent in group $\mathrm{C}$ were used to watching television followed by reading newspapers/ magazines ( 20 and 23\%) whereas 17 percent subjects in both the groups were used to sit idle for relaxation in group $\mathrm{E}$ and $\mathrm{C}$ respectively. Meditation and worshipping were used as relaxation technique in 23 percent of the subjects in group $\mathrm{E}$ and 30 percent in group $\mathrm{C}$ respectively.

Table 1 Background information of the subjects

\begin{tabular}{cccc}
\hline Variables & $\begin{array}{c}\text { Experimental } \\
\text { Group }(\mathbf{n = 3 0})\end{array}$ & $\begin{array}{c}\text { Control Group } \\
(\mathbf{n = 3 0})\end{array}$ & $\begin{array}{c}\text { Total } \\
(\mathbf{N}=\mathbf{6 0})\end{array}$ \\
\hline Age (mean \pm S.E) & $46.53 \pm 0.48$ & $47.2 \pm 0.29$ & $46.86 \pm 0.38$ \\
Education & & & \\
Graduate & $18(60)$ & $25(83)$ & $43(72)$ \\
Post Graduate & $12(40)$ & $5(17)$ & $17(28)$ \\
Job responsibility & $20,400 \pm 1386$ & $24,200 \pm 1526$ & $22,300 \pm 1456$ \\
Deskwork & & & \\
Touring & $25(83)$ & $26(87)$ & $51(85)$ \\
Lab work & $3(10)$ & $4(13)$ & $7(12)$ \\
Monthly Income (Mean \pm S.E.) & $2(7)$ & - & $2(3)$ \\
Scooter & $8(26)$ & $8(26)$ & $16(27)$ \\
Cycle & $14(48)$ & $18(60)$ & $32(53)$ \\
Commute to work place & $1(3)$ & $2(7)$ & $3(5)$ \\
\hline
\end{tabular}




\begin{tabular}{cccc}
\hline Bus & $7(23)$ & $2(7)$ & $9(15)$ \\
Exercise & & & \\
Walking & $4(13)$ & $5(17)$ & $9(15)$ \\
Brisk walking & $3(10)$ & $4(13)$ & $7(12)$ \\
None & $23(77)$ & $21(70)$ & $44(73)$ \\
Relaxation & & & \\
Worshipping & $7(23)$ & $9(30)$ & $16(27)$ \\
Viewing Television & $24(80) \$$ & $27(90) \$$ & $51(85)$ \\
Reading & $6(20)$ & $7(23)$ & $13(21)$ \\
idle sitting & $5(17)$ & $5(17)$ & $10(17)$ \\
Alcohol consumption & & & \\
Yes & $17(57)$ & $14(47)$ & $31(52)$ \\
No & $13(43)$ & $16(53)$ & $29(48)$ \\
Family history & & \\
Diabetes & $8(27) \$$ & $8(27) \$$ & $16(27)$ \\
Hypertension & $5(17)$ & $6(20)$ & $11(18)$ \\
Hyperlipidemia & $6(20) \$$ & $7(23) \$$ & $13(21)$ \\
Obesity & $10(33) \$$ & $12(40) \$$ & $22(37)$ \\
Heart attack & $1(3)$ & $2(7)$ & $3(5)$ \\
None & $12(40)$ & $9(30)$ & $21(35)$ \\
\hline
\end{tabular}

The mean daily intake of nutrients by the subjects is presented in Table 2 . The data revealed that the initial mean daily energy intake of the subjects in E and C group was 2288.11 and 2427.62 Kcal which reduced to 2048.52 and 2240.58 respectively after the nutrition counselling.

Table 2 Mean daily macronutrient intake of the subjects before and after the study (Mean $\pm \mathrm{SE}$ )

\begin{tabular}{ccccccc}
\hline $\begin{array}{c}\text { Group } \\
(\mathbf{n}=\mathbf{3 0})\end{array}$ & Variables & Before study & After study & $\begin{array}{c}\text { \% } \\
\text { change }\end{array}$ & t value & $\begin{array}{c}\text { Reference } \\
\text { standards }\end{array}$ \\
\hline E & Energy (Kcal) & $2288.11 \pm 28.3$ & $2048.52 \pm 27.44$ & 10.47 & $6.65^{* *}$ & $\begin{array}{c}1800-2400 \\
\text { kcal }\end{array}$ \\
& & 2 & & & & \\
C & & $2427.62 \pm 23.5$ & $2240.58 \pm 13.7$ & 7.70 & $3.31^{* *}$ & \\
E & Protein (g) & $57.76 \pm 1.20$ & $65.56 \pm 1.04$ & 13.50 & $3.32^{* *}$ & $50-60 \mathrm{~g}$ \\
C & & $66.41 \pm 0.77$ & $67.22 \pm 0.53$ & 1.22 & $1.61^{\mathrm{NS}}$ & \\
E & Carbohydrates & $339.87 \pm 5.77$ & $312.40 \pm 5.65$ & 8.09 & $4.53^{* *}$ & $300-340 \mathrm{~g}$ \\
C & $(\mathrm{g})$ & $377.26 \pm 7.86$ & $346.97 \pm 10.23$ & 7.98 & $2.37^{*}$ & \\
E & Total fat (g) & $69.86 \pm 1.75$ & $55.53 \pm 0.66$ & 20.51 & $4.75^{* *}$ & $40-60 \mathrm{~g}$ \\
C & & $72.68 \pm 4.2$ & $70.19 \pm 0.76$ & 3.41 & $1.09^{\mathrm{NS}}$ & \\
E & Fibre (g) & $8.02 \pm 1.10$ & $15.32 \pm 0.94$ & 91.5 & $3.26^{* *}$ & $40 \mathrm{~g}$ \\
C & & $8.46 \pm 0.55$ & $13.56 \pm 0.16$ & 60.28 & $2.09^{*}$ & \\
\hline
\end{tabular}


${ }^{* *}$ Significant at $1 \%$ level of significance

${ }^{*}$ Significant at $5 \%$ level of significance

${ }^{\text {NS }}$ Non significant

\# Ghafoornissa and Krishnaswamy (2000) [11]

Mean daily protein intake before and after study was 57.76 and $65.56 \mathrm{~g}$ in the subjects of group E and 66.41 and $67.22 \mathrm{~g}$ in the subjects of group $\mathrm{C}$ respectively. The increase was reported as the subjects had increased their consumption of milk \& milk products and pulses. The initial and final mean intake of carbohydrates was 339.87, $377.26 \mathrm{~g}$ and 312.40 and $366.97 \mathrm{~g}$ in group E and C respectively. The initial mean daily fat intake was 69.86 and $72.68 \mathrm{~g}$ which reduced to 55.532 and $70.19 \mathrm{~g}$ in group $\mathrm{E}$ and $\mathrm{C}$ respectively. The average daily consumption of fiber by the subjects before study was 8.02 and $8.46 \mathrm{~g}$ in group $\mathrm{E}$ and $\mathrm{C}$ respectively which increased significantly to 15.32 and 13.56 after the study. The increase in fiber intake could be due to the counselling about beneficial affects of fiber, decrease fat absorption, bind bile acids and lower cholesterol levels and thus help in management of hyperlipidemia. The subjects were told about the fiber rich foods which are easily available, easy to cook and give more satiety value like whole wheat flour, whole pulses, whole cereals, fruits with peel etc.

Anthropometric assessment- Anthropometric measurements of the subjects are presented in Table 4. The mean height of the subjects in $\mathrm{E}$ and $\mathrm{C}$ groups was $1.65,1.68 \mathrm{~cm}$ respectively. Thus the subjects of the present study were little shorter. Mean weight of the subjects was 71.43 and $74.08 \mathrm{~kg}$ before the study in group $\mathrm{E}$ and $\mathrm{C}$ consequent to supplementation and nutrition counselling there was significant $(p<0.01)$ reduction of $3.65 \%$ in the weight of the subjects in group E. The decrease could be due to reduction in total energy intake. Decrease in weight of control group was also observed. The mean weight of the subjects after the study was 69.71 and $73.59 \mathrm{~kg}$ in group $\mathrm{E}$ and $\mathrm{C}$ respectively. But the average weight of the subjects was higher in all the groups as compared to standards $(60 \mathrm{~kg})$. The BMI values among the subjects decreased from 26.17 and $26.20 \mathrm{~kg} / \mathrm{m}^{2}$ to 25.53 and $26.0 \mathrm{~kg} / \mathrm{m}^{2}$ after the study period in groups $\mathrm{E}$ and $\mathrm{C}$ respectively. Due to decrease in weight a statistically significant decrease was reported in BMI in group A $(\mathrm{p}<0.05)$ whereas a non significant decrease was observed in group $\mathrm{C}$. The mean BMI values were higher than standard values of $18-24.99 \mathrm{~kg} / \mathrm{m} 2$ in all the three groups.

Table 3. Anthropometric profile of the subjects before and after the study (Mean $\pm \mathrm{SE}$ )

\begin{tabular}{ccccccc}
\hline $\begin{array}{c}\text { Group } \\
(\mathbf{n}=\mathbf{3 0})\end{array}$ & Variables & Before study & After study & $\begin{array}{c}\text { \% } \\
\text { change }\end{array}$ & t value & $\begin{array}{c}\text { Reference } \\
\text { standards } \boldsymbol{\Omega}\end{array}$ \\
\hline $\mathrm{E}$ & $\mathrm{Ht}(\mathrm{cm})$ & $1.65 \pm 0.01$ & & & & $1.71 \mathbf{\square}$ \\
$\mathrm{C}$ & & $1.68 \pm 0.06$ & & & & \\
$\mathrm{E}$ & $\mathrm{Wt}(\mathrm{Kg})$ & $71.43 \pm 0.95$ & $69.71 \pm 0.98$ & 3.65 & $2.33^{*}$ & $60 \#$ \\
$\mathrm{C}$ & & $74.08 \pm 0.18$ & $73.59 \pm 0.18$ & 0.66 & $1.53^{\mathrm{NS}}$ & \\
$\mathrm{E}$ & $\mathrm{BMI}$ & $26.17 \pm 0.12$ & $25.53 \pm 0.11$ & 2.45 & $2.96^{* *}$ & $18.5-24.9^{@}$ \\
$\mathrm{C}$ & $\left(\mathrm{Kg} / \mathrm{m}^{2}\right)$ & $26.20 \pm 0.16$ & $26.0 \pm 0.16$ & 0.76 & $1.23^{\mathrm{NS}}$ & \\
\hline
\end{tabular}




\begin{tabular}{ccccccc}
\hline E & Body fat \% & $27.06 \pm 0.04$ & $26.98 \pm 0.04$ & 0.29 & $0.05^{\mathrm{NS}}$ & $25 \%$ \\
$\mathrm{C}$ & & $27.08 \pm 0.04$ & $27.03 \pm 0.04$ & 0.18 & $0.02^{\mathrm{NS}}$ & \\
\hline
\end{tabular}

${ }^{* *}$ Significant at $1 \%$ level of significance, $\quad{ }^{*}$ Significant at $5 \%$ level of significance

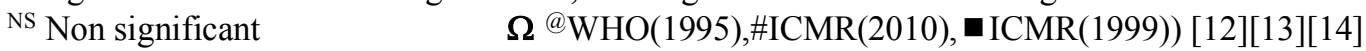

The mean skinfold thickness at biceps, triceps, subscapular and suprailliac were calculated and added to calculate body fat percent. The mean body fat in group E and $\mathrm{C}$ was 27.06 and 27.08 percent respectively before the study. These values exceeded the normal fat range (16-20\%) in all the groups, representing excess fat deposition in all the groups owing to overweight or obesity. The mean body fat after the study in group $\mathrm{E}$ and $\mathrm{C}$ was 26.98 and 27.03 percent respectively.

Lipid profile is evaluated for its role in cardiovascular disease. In the present study lipid profile of both the groups is depicted in Table 5. The mean cholesterol of the subject of group E was 265.83 and $233.1 \mathrm{mg} / \mathrm{dl}$ before and after the supplementation where as in the subject of group $\mathrm{C}$ values were 259.43 and $254.07 \mathrm{mg} / \mathrm{dl}$. There was as 12.31 percent reduction in serum cholesterol of subject of amla $+\mathrm{NC}$ supplemented group i.e. group E.

Table 4 Lipid profile of the subjects before and after the study (Mean \pm SE)

\begin{tabular}{ccccccc}
\hline $\begin{array}{c}\text { Group } \\
(\mathbf{n}=\mathbf{3 0})\end{array}$ & Variables & Before study & After study & $\begin{array}{c}\text { \% } \\
\text { change }\end{array}$ & t value & $\begin{array}{c}\text { Reference } \\
\text { standards\# }\end{array}$ \\
\hline A & Total & $265.83 \pm 4.92$ & $233.1 \pm 5.17$ & 12.31 & $3.65^{* *}$ & $<200$ \\
C & $\begin{array}{c}\text { cholesterol } \\
(\mathrm{mg} / \mathrm{dl})\end{array}$ & $259.43 \pm 5.82$ & $254.07 \pm 5.68$ & 1.90 & $1.30^{\mathrm{NS}}$ & \\
$\mathrm{A}$ & $\begin{array}{c}\mathrm{HDL} \\
\text { cholesterol } \\
(\mathrm{mg} / \mathrm{dl})\end{array}$ & $43.56 \pm 0.62$ & $47.13 \pm 0.63$ & 8.19 & $2.75^{* *}$ & $40-70$ \\
$\mathrm{C}$ & $40.8 \pm 0.75$ & $41.07 \pm 0.73$ & 0.4 & $0.22^{\mathrm{NS}}$ & \\
$\mathrm{A}$ & $\begin{array}{c}\text { LDL } \\
\text { cholesterol } \\
(\mathrm{mg} / \mathrm{dl})\end{array}$ & $165.17 \pm 5.20$ & $145.86 \pm 4.44$ & 11.69 & $3.48^{* *}$ & $80-160$ \\
$\mathrm{C}$ & $170.13 \pm 7.84$ & $169.37 \pm 7.68$ & 0.45 & $0.42^{\mathrm{NS}}$ & \\
$\mathrm{A}$ & $\begin{array}{c}\text { Triglycerides } \\
\text { (mg/dl) }\end{array}$ & $232.57 \pm 8.91$ & $194.96 \pm 9.56$ & 16.17 & $2.96^{* *}$ & $<150$ \\
$\mathrm{C}$ & $249.23 \pm 7.76$ & $240.46 \pm 8.20$ & 3.51 & $1.33^{\mathrm{NS}}$ & \\
$\mathrm{A}$ & $\begin{array}{c}\text { VLDL } \\
\text { cholesterol } \\
(\mathrm{mg} / \mathrm{dl})\end{array}$ & $46.51 \pm 1.7$ & $38.99 \pm 1.90$ & 16.17 & $2.96^{* *}$ & $<40$ \\
$\mathrm{C}$ & $49.85 \pm 1.55$ & $48.09 \pm 1.64$ & 3.53 & $1.33^{\mathrm{NS}}$ & \\
\hline${ }^{* *}$ Significant at $1 \%$ level of significance & ${ }^{*}$ Significant at $5 \%$ level of significance & \\
NS Non significant & & \# Ghafoorunissa and Krishnaswamy 2000 [11]
\end{tabular}

HDL-C also known as good cholesterol as it decreases risk of CHD by reverse cholesterol transport i.e. it carries excess cholesterol from peripheral cells back to the liver for removal the body. The mean HDL cholesterol in the present study was 43.56 and $47.13 \mathrm{mg} / \mathrm{dl}$ in the subject of 
group $\mathrm{E}$ before and after amla and NC supplementation. The mean values were 40.8 and 41.07 $\mathrm{mg} / \mathrm{dl}$ in group C before and after nutrition counseling. There was $8.19 \%$ increase in the HDL- C of the subjects of group A. LDL-cholesterol value before the study was 165.17 and $170.13 \mathrm{mg} / \mathrm{dl}$ in group $\mathrm{E}$ and $\mathrm{C}$ respectively which reduced to 145.86 and $169.37 \mathrm{mg} / \mathrm{dl}$ respectively after the study. There was 11.69 percent reduction in LDL-C of the subjects of group E. Mean values of triglycerides before and after the study were 232.57 and $194.96 \mathrm{mg} / \mathrm{dl}$ in the subjects of group E supplemented with amla powder and nutrition counselling and 249.23 and $240.46 \mathrm{mg} / \mathrm{dl}$ in the subjects of group $\mathrm{C}$ provided with nutrition counselling only. A significant decrease of 16.17 percent was observed in the subjects of group A. The VLDL-C levels in all the subjects were higher than normal value $(<30 \mathrm{mg} / \mathrm{dl})$. The mean VLDL-C levels were 46.51 and $49.85 \mathrm{mg} / \mathrm{dl}$ before the study in the subjects of group $\mathrm{E}$ and $\mathrm{C}$ respectively which was reduced to 38.99 and $48.09 \mathrm{mg} / \mathrm{dl}$ respectively after the study. In the subjects of group $\mathrm{C}$ treated as control and supplemented with $\mathrm{NC}$ only there was $1.9 \%$ reduction in their serum cholesterol.

\section{Discussion}

\subsection{Background and lifestyle Information of the subjects}

The selected 60 volunteer hyperlipidemic males were in the age group of 39- 49 years, the fourth decade of life is considered as the prime period of developing risk of coronary heart disease. Age, gender and heredity are found to be modifying aspects in hyperlipidemia progression. [15] Age is also a significant predictor of cholesterol values and BMI, as levels of cholesterol and glucose surges across the life span. [17] Indians are affected by CVD in their most productive midlife years. [16] Highly educated men and women in countries where malnutrition is prevalent, tend to have higher BMI than less educated people. [18] Meditation and worshipping were relaxation techniques followed among our participants. Meditation, time tested ancient Indian technique of relaxation can produce wonders. Recent studies have shown regular meditation improved immunity level and also produced antibodies. It also brought biological changes in the brain which makes person calm and stress free. [19] More than 50 percent of the subjects were in habit of consuming alcohol. High alcohol consumption is associated with hypertension, hyperlipidemia and reduced glucose tolerance and irregular heart-beat. Heredity or family history of non-communicable diseases like diabetes, hypertension and hyperlipidemia increases the risk of coronary heart disease. Genes regulate amount of cholesterol manufactured by the body. [21] Family history of CHD, diabetes, hypertension and hyperlipidemia are related to CHD. [22] [23]

\subsection{Nutrient intake}

High intake of total fat, saturated fat and dietary cholesterol contributes to the elevated risk of CVD. [24] An unhealthful lifestyle inclusive of high dietary fat, overweight, smoking, high alcohol consumption and absence of exercise gives rise to aberrant cholesterol levels. [25] A study on 400 men by National Institute of ageing, showed cutting calories decreases 
atherosclerosis by 40 per cent, improves insulin sensitivity, reduces BMR and decreases free radicals. [26]

\subsection{Anthropometric measures}

The average height suggested for Indian man is $171 \mathrm{~cm}$. [14] According to Kaur and Bains (2004) Punjabis in the age group of 40-60 years was reported to be $168.9 \mathrm{~cm}$. [27] During the study, in nutrition counselling sessions, all the subjects were advised to introduce 30 minutes of physical activity in their daily routine, as well as limit amount of fat intake which led to reduction in weight. Weight loss of approximately $5-10 \%$ of body weight can reduce the risk for heart attack. Decrease in body weight was reported as result of counselling. [28] It was reported that obesity, increased BMI, and waist-hip ratio were the contributing factors towards the increased risk of cardiovascular disease. [25] Excess adiposity was most important predictor of diabetes and CVD. [29] It was stated that men in the highest BMI quintile i.e. $\geq 27.6 \mathrm{~kg} / \mathrm{m}^{2}$ had a relative risk of 1.73 for CHD compared with those who lied in the normal BMI range. [30] Excess adiposity is the most important risk factor for CVD. [11] [20]

\subsection{Intervention -Amla and Nutrition counselling}

High blood cholesterol plays an important role in development of cardiovascular diseases. A significant reduction in lipid profile of CHD patients provided with NC for 4 months was also reported by Sangha and Baring (2003). [31] Physical inactivity is the one of the main risk factors which increases individual risks to cardiovascular diseases and. WHO recommended 30 minutes of exercise a day for basic level of fitness and similar findings were also observed. [32] It was suggested that regular exercise promotes positive improvement in lipid profile and mental relaxation.[33]

Reducing cholesterol by $1 \%$ reduces incidence of CHD by $2 \%$. As currently available drug statin has certain drawbacks hence, there is a need for safer and more effective hypolipidemic agents. Therefore, in the present study we assessed the hypolipidemic potential of E officinalis which is a herbal plant of India and is widely used in medicinal preparations. In the present study a reduction of $12.13 \%$ in total cholesterol was observed in hyperlipidemic subjects. This reduction by E.

officinalis powder can be a strategic intervention in reducing hyperlipidemia. Previously the effect of amlamax (amla extract) on hyperlipidemic subjects was studied and a significant reduction in total serum cholesterol (17\%), LDL cholesterol $(21 \%)$ and remarkable elevation in HDL cholesterol by $14 \%$ was found. [6] Another reason for choosing E officinalis for the present study was due to its capacity to reduce elevated cholesterol, triglyceride and LDL-C concentration which is an essential trigger for body to revert to its normal homeostasis. The possible mechanism by which $\mathrm{E}$ officinalis exerts its hypolipidemic action is by inhibition of Hepatic 3 hydroxy -3 methyl glutaryl coenzyme A (HMGCoA) reductase enzyme thereby interfering with the synthesis of cholesterol. Our findings coincide with earlier studies which reported that an extract of $\mathrm{E}$ officinalis reduced the serum cholesterol and increased HDL-Cholesterol in dyslipidemic patients. 
[6] E officinalis is reported to upregulate the enzymes responsible for transfer of cholesterol from low density lipoprotein to high density lipoprotein (Antony 2008).[6]

\section{Conclusion}

Amla powder supplementation and nutrition counselling had a significant effect in the improvement of lipid profile of the subjects as indicated from the decrease in total cholesterol, LDL-C, VLDL-C, TC: HDL-C and LDL: HDL-C and increase in HDL-C. Thus, supplementation of $5 \mathrm{~g} E$ officinalis (amla) powder and nutrition counselling can be an effective strategic dietary intervention for controlling serum lipid profile in hyperlipidemic male subjects. With increasing toll of NCDs, associated health care cost and disability adjusted life years, we certainly need to find indigenous solutions which can successfully manage hyperlipidemia, arrest progression of coronary heart diseases and reduce the risk of drug side effects too. Customized nutrition counselling is also very important to create awareness regarding hyperlipidemia, its long-term effects, as well as its management. Ample of physical activity should also be encouraged to keep hyperlipidemia in check.

\section{References}

[1]. Amit G, Vandana S, Sidharth M.: Hyperlipidemia: An Updated Review. Inter J of Biopharma \& Toxicol Res. Vol.1.pp.81-89. (2011)

[2]. Vasanthi, Hannah R. R P Parameswari.: Indian spices for healthy heart - an overview. Current cardiology reviews. Vol.6.pp.274-279. (2010)

[3]. Ali SS, Kasoju N, Luthra A, Singh A, Sharanabasav H, Sahu A, Bora U.: Indian medicinal herbs as sources of antioxidants. Food Intern J. Vol.41.pp.115. (2008)

[4]. https://www.deccanherald.com/opinion/panorama/the-rising-threat-of-heartdisease-777809.html

[5]. Philip Barter: The role of HDL-cholesterol in preventing atherosclerotic disease. European Heart Journal Supplements.Vol.7.suppl_F. pp F4-F8. (2005)

[6]. Antony B, Merina B and Sheeba V.: Amlamax in the management of dyslipidemia. Indian J Pharma Sci Vol.70.pp.504-507. (2008)

[7]. Duan W, Yu Y, Zhang L.: Antiatherogenic effects of Phyllanthus emblica associated with corilagin and its analogue. Yakugaku Zasshi. Vol.125.pp.587-91. (2005)

[8]. Goyal M.: Development and organoleptic evaluation of amla (Phyllanthus emblica) powder for nutritional benefits. M.Sc. Thesis, Punjab Agricultural University, Ludhiana. (2007)

[9]. AOAC. Official Methods of Analysis. Association of Official Analytical Chemists. Washington D.C (1980)

[10]. Bansal M L, Singh S, Singh T P and Kumar R.: Statistical method for research workers. pp 213-221. Kalyani Publishers, Ludhiana. (2004) 
[11]. Ghafoorunissa and Krishnaswamy K.: Diet and Heart Disease. National Institute of Nutrition, Hyderabad. (2000)

[12]. WHO World health statistics annual, Geneva. (1995)

[13]. Indian Council of Medical Research. Recommended dietary allowances for Indians: A report of the expert group of the ICMR, National Institute of Nutrition, Hyderabad (2010)

[14]. ICMR. Dietary guidelines for Indians- A manual, Indian Council of Medical Research, National Institute of Nutrition, Hyderabad. (1999)

[15]. Balk EM, Lau J, Goudas LC, Jordan HS, Kupelnick B, Kim LU, Karas RH.: Effects of statins on nonlipid serum markers associated with cardiovascular disease: a systematic review. Annals of Internal Medicine. Vol.139.pp.670682. (2003)

[16]. Joshi P, Islam S, Pais P, Reddy S, Dorairaj P, Kazmi K, Pandey MR, Haque S, Mendis S, Rangarajan S, Yusuf S. Risk factors for early myocardial infarction in South Asians compared with individuals in other countries. JAMA. 294.pp.286-294. doi: 10.1001/jama.297.3.286. (2007)

[17]. Jackson R T, Al Mousa Z, Al Raqua M, Prasanna P and Ali Muhanna.: Prevalence of coronary risk factors in healthy adult Kuwaitis. Intern J Food Sci and Nutr Vol.52.pp.301-11. (2001)

[18]. Anonymous.: Study highlights heart disease risk in India. In Rxpress, The Indian Express, April 26. (2008)

[19]. Anonyms (2006) Young heart at risk. Saturday Extra, The Tribune, Dec 16.

[20]. Center for Disease Control and Prevention. Atlanta: U.S. Department of Health and Human Services; . QuickStats: Average Total Cholesterol Level Among Men and Women; p. 1045. (2009)

[21]. Mukamal K J, Ascherio A, Mittleman MA and Rumin E B.: Alcohol and risk for ischemic stroke in men: the role of drinking patterns and usual beverage. Ann Intern Med. Vol.42:pp124. (2005)

[22]. Sachan and Mogra.: Assessment of pre disposing risk factors of cardiovascular disease among young males. The Ind J Nutr Dietet. Vol.41.pp. 375-85. (2003)

[23]. Mehta M.: Cardiac risk assessment tool to correlate thrombosis with dietary fatty acids. Ind J Nutr Diet Vol.41: pp.165-73. (2004)

[24]. Vasanthamani and Easwaran P. :Epidemiology of diseases in relation to consumption pattern of fats and oils among selected adults in Coimbatore city. Ind J Nutr Dietet. Vol.37.pp.103-108. (2000)

[25]. Singh A and Choudhry M.: Atherogenic profile of patients at an increased risk of cardiovascular disease Ind J Nutr Dietet Vol.44.pp.301-312. (2007)

[26]. Khosla I (2008) Seedy Drive. In body+mind, The Indian Express, March 16.

[27]. Kaur J and Bains K.: Determinants of cardiovascular disease among rural Punjabi males. M.Sc. Thesis Punjab Agricultural University, Ludhiana, India. (2004)

[28]. Lauber and Nancy S F.: The American Heart Association. Dietary Guidelines for 2000: A summary report. Nutr Rev Vol.59.pp.298-306. (2001) 
[29]. Schulze M B and Hu F B.: Primary prevention of diabetes: What can be done and how much can be prevented? Annu Rev Public Health. Vol.26.pp.445-467. (2005)

[30]. Rexrode K M, Buring J E and Manson J E.: Abdominal and total adiposity and risk of coronary heart disease in men Int J Obesity Vol.25.pp.1047-1056. (2001)

[31]. Sangha J K and Baring P.: Efficacy of multiple dietary therapies in reducing risk factors for coronary heart disease. J Human Ecol 14:33-36. (2003)

[32]. Grewal G S.: Exercise and ischemic heart disease In: Ludhiana Tribune, The Tribune, September 16. (2000)

[33]. Wasir H S.: Exercise daily for your heart's sake. The Tribune, Apr 7. (2002) 